\title{
REVIEW
}

\section{Biodiversity of benthic assemblages on the Arctic continental shelf: historical data from Canada}

\author{
Mathieu Cusson ${ }^{1,4}$, Philippe Archambault ${ }^{2,5, *}$, Alec Aitken ${ }^{3}$ \\ ${ }^{1}$ Département de Biologie, Québec-Océan (GIROQ), Université Laval, Québec G1K 7P4, Canada \\ ${ }^{2}$ Sciences de l'Habitat, Institut Maurice-Lamontagne, Pêches et Océans Canada, CP 1000, Mont-Joli, Québec G5H 3Z4, Canada \\ ${ }^{3}$ Department of Geography, University of Saskatchewan, 9 Campus Drive, Saskatoon, Saskatchewan S7N 5A5, Canada \\ ${ }^{4}$ Present address: School of Biology and Environmental Science, University College Dublin, Belfield, Dublin 4, Ireland \\ ${ }^{5}$ Present address: Institut des Sciences de la Mer de Rimouski (ISMER), Université du Quebec à Rimouski, \\ 310 Allée des Ursulines, Rimouski, Quebec G5L 3A1, Canada
}

\begin{abstract}
This study describes patterns of abundance, diversity, and assemblages of benthic macrofauna within the Canadian Arctic Archipelago. A review of data reports and the published literature yielded 219 stations and 947 taxa from 7 sources in various regions of the Canadian Arctic Archipelago (i.e. Beaufort Sea and Mackenzie Shelf, Victoria Island, Hudson and James Bays, Frobisher Bay, Ungava Bay, and Southern Davis Strait). In general, we observed that eastern regions of the Canadian Arctic Archipelago showed greater values of species richness (or $\alpha$ diversity) than the western and central regions, whereas no specific patterns were observed for Shannon-Wiener's diversity $\left(H^{\prime}\right)$ and Pielou's evenness $\left(J^{\prime}\right)$ indices. The Beaufort Sea and Mackenzie Shelf region exhibited high values of taxonomic distinctness $\left(\Delta^{+}\right)$, whereas Hudson Bay showed low values. However, the Hudson Bay region showed high values of turnover $\left(\beta_{\mathrm{W}}\right)$ diversity. A non-metric multi-dimensional scaling plot of similarity (Bray-Curtis index) and analysis of similarity revealed that species composition differed among regions, even those located in close proximity to one another. These investigations were conducted at different levels of taxonomic resolution (Species, Order, Class and Phyla) and the results demonstrated that most patterns were maintained up to the Order and Class level. A relatively small number of taxa, mainly annelids, were responsible for most of the dissimilarity among regions. Bottom salinity and temperature were the most important environmental variables (among depth of site, bottom temperature, salinity, physical and chemical sediment characteristics) for determining these assemblage patterns. Multiple regression analyses also demonstrated that variance in species richness and diversity $\left(H^{\prime}\right)$ was best explained by variance in salinity (55 and $43 \%$ respectively). The analysis of a time series from Frobisher Bay revealed that the temporal (mo/yrscale) variability of assemblages was of the same order as the spatial ( $\mathrm{km}$-scale) variability among sites.
\end{abstract}

KEY WORDS: Benthic assemblage - Meta-analysis - Historical data - Arctic macrobenthos · Multivariate analysis $\cdot \alpha, \gamma$, and turnover $(\beta)$ diversity $\cdot$ Spatial and temporal variability

\section{INTRODUCTION}

Within the last 2 decades, research on the macrobenthos of the Arctic continental shelves has shifted from being largely descriptive to a process-oriented approach (e.g. Piepenburg 2005). Baseline information such as species inventories, patterns of abundance, and comparisons of biodiversity among Arctic regions remains difficult to find. Furthermore, despite the urgency to address observations of biodiversity patterns at larger scales (i.e. global Canadian Arctic), the emphasis of biodiversity research on the Arctic benthos has been focused at local to regional scales (e.g. Bluhm et al. 2005, Conlan \& Kvitek 2005). Research at a 
broader scale has been impeded by 2 major factors. The first is the considerable technical difficulty of sampling the Arctic environment at scales greater than local or regional; the only way to solve this problem is to gather and compare data from many studies and/or use historical data. The second is that the richly diverse fauna requires great taxonomic skills to provide a consistent and reliable inventory. If these 2 factors could be overcome, the description of past variability in benthic community structure may help to track future potential modifications brought about by changes (i.e. increasing temperature and sea level, glaciers melting, etc.) experienced at large scales in the Arctic environment (e.g. Moritz et al. 2002, ACIA 2005, Polyakov et al. 2005).

Many proxies have been used to follow changes in the environment, including the Shannon-Wiener diversity index $\left(H^{\prime}\right)$ and species richness. These are widely used and considered to be good indicators of community structure. Recently, biodiversity has been related to spatial scale using various measurements (e.g. $\alpha, \gamma$ and turnover [ $\beta$ ] diversity) (e.g. Gray 2000, Magurran 2004). However, these univariate variables may stay constant whereas species composition may change (e.g. Clarke \& Warwick 2001a, Bertocci et al. 2005). Indeed, multivariate analyses can often reveal or illustrate patterns in diversity and species richness where univariate analyses cannot (Gray et al. 1990). It has become common to use measures of community assemblage similarities (in term of species composition and abundance) to circumvent the loss of information inherent in univariate summaries of community structure (Downes et al. 2002). Changes in species composition and dominance in benthic communities have been detected along environmental gradients (e.g. Warwick \& Clarke 1993), or in response to pollution disturbance (e.g. Warwick \& Clarke 1993, Harkantra \& Rodrigues 2004) and natural spatial variability (e.g. Somerfield \& Gage 2000, Clarke \& Warwick 2001a). Multivariate analyses are more robust at detecting transformations that can occur in species abundance and dominance in a community. Applying such tools to historical data may provide insights into the state of historical communities.

Historical data from the Canadian Arctic Archipelago include long-term field experiments on the effects of oil spillage in arctic waters (e.g. Cross et al. 1987, Cross \& Thomson 1987), as well as quantitative (density and biomass) studies of benthos across the continental shelf and slope (Thomson 1982, Dunton et al. 2005) and within fjords (Syvitski et al. 1989, Aitken \& Fournier 1993). There has been a progressive thinning and shorter duration of sea ice cover in the Arctic in general (e.g. Serreze et al. 2003, Comiso \& Parkinson 2004) and in many of the Canadian Arctic regions (e.g. Barber \& Hanesiak 2004, Belchansky et al. 2004, Gagnon \& Gough 2005). This, coupled with the likely future exploitation of the Canadian Arctic for marine transport, has created a need to establish baseline data on the state of the marine environment using new statistical tools for comparisons with contemporary studies. To achieve this goal, the importance of using grey literature (e.g. technical reports, government documents, unpublished manuscripts) to enlarge the database should not be underestimated. The objectives of this paper were to use such data to: (1) characterize and evaluate differences in benthic macrofaunal species richness, $\alpha, \beta$ and $\gamma$ diversity, and assemblages from historic data sets within the Canadian Arctic regions; (2) compare the relative importance of spatial and temporal variability of species assemblages from those sites with temporal data; and (3) evaluate the correlation between benthic assemblages and the environmental variables for which we have good information.

\section{MATERIALS AND METHODS}

Faunal samples. The literature on historical data related to Canadian Arctic benthos was reviewed. We retained sites for which macrobenthos community data sets from marine and estuarine environments in the Canadian Arctic were available (Table 1). Only data from standardized grabs (van Veen, Ponar, Eckman etc.) were retained to enable comparisons among sites. A total of 219 stations were used (Table 1, Fig. 1). Each station was represented by 1 to 10 grabs (median: 4.5) for which the sampled areas were between 0.09 and $1.2 \mathrm{~m}^{2}$ (median: 0.25). Mean densities per station were used. Most data sets used in this study are from technical reports of the Department of Environment and Fisheries and Oceans Canada, but data from some regions (Southern Davis Strait and Ungava Bay) are from published literature (Stewart 1983, Stewart et al. 1985). Data were obtained from many regions (Beaufort Sea and Mackenzie Shelf: BM; Victoria Island: $V_{\text {; }}$ Hudson Bay: HB; James Bay: JB; Ungava Bay: UB; Frobisher Bay: F; Southern Davis Strait: DS) and allowed a broad east-west comparison of benthic assemblages across the Canadian Arctic. Information from some of the regions (e.g. Victoria Island, Hudson Bay) consists only of presence/absence information for each species (i.e. simple species lists). Four sampling time series (with 2, 5, 9, and 10 dates) from Frobisher Bay were available. Delimitation of these regions was mainly based on the zoogeographic subdivision of Canadian Arctic mollusc fauna from Lubinsky (1980) (with a subdivision for Frobisher and Ungava Bay) as well as the Arctic and the sub-Arctic regions described by Curtis (1975). When available, physical data associated with biological data (e.g. depth, bottom temperature and 
Table 1. Stations from the Canadian Arctic included in meta-analysis. L: list of species; D: mean density per species

\begin{tabular}{|c|c|c|c|c|}
\hline Regions & Date (no. of stations) & $\begin{array}{l}\text { Total no. stations } \\
\text { per region }\end{array}$ & Type of data set & Source \\
\hline Hudson Bay (HB) & $\begin{array}{l}1955(1) ; 1958(4) ; 1959(1) ; \\
1961(6) ; 1965(49)\end{array}$ & 61 & $\mathrm{~L}^{\mathrm{a}}$ & 1: Atkinson \& Wacasey (1989a) \\
\hline James Bay (JB) & $1974(17)$ & 17 & $D^{b, c, f}$ & 2: Wacasey et al. (1976) \\
\hline Victoria Island (V) & $1967(4) ; 1968(4) ; 1969(2)$ & 10 & $D \& L^{a}$ & 3: Atkinson \& Wacasey (1989b) \\
\hline $\begin{array}{l}\text { Beaufort Sea and } \\
\text { Mackenzie Shelf (BM) }\end{array}$ & $\begin{array}{l}1971(6) ; 1973(17) ; 1974(16) ; \\
1975(62)\end{array}$ & 101 & $\mathrm{D}^{\mathrm{b}-\mathrm{e}}$ & 4: Wacasey et al. (1977) \\
\hline $\begin{array}{l}\text { Frobisher Bay, } \\
\text { Baffin Island (F) }\end{array}$ & $\begin{array}{l}1967(1) ; 1968(8) ; 1969(7) ; \\
1970(2)\end{array}$ & $5^{\mathrm{A}}$ & $\mathrm{D}^{\mathrm{b}}$ & 5: Wacasey et al. (1979) \\
\hline $\begin{array}{l}\text { Frobisher Bay, } \\
\text { Baffin Island }(\mathrm{F})\end{array}$ & $\begin{array}{l}1969(2) ; 1970(2) ; 1972(2) ; \\
1973(7) ; 1976(2)\end{array}$ & $6^{\mathrm{B}}$ & $\mathrm{D}^{\mathrm{b}}$ & 6: Wacasey et al. (1980) \\
\hline $\begin{array}{l}\text { Southern Davis Strait (DS) } \\
\text { and Ungava Bay (UB) }\end{array}$ & $1977(13)$ & 13 & $D^{f}$ & 7: MacLaren MAREX (1978) \\
\hline
\end{tabular}

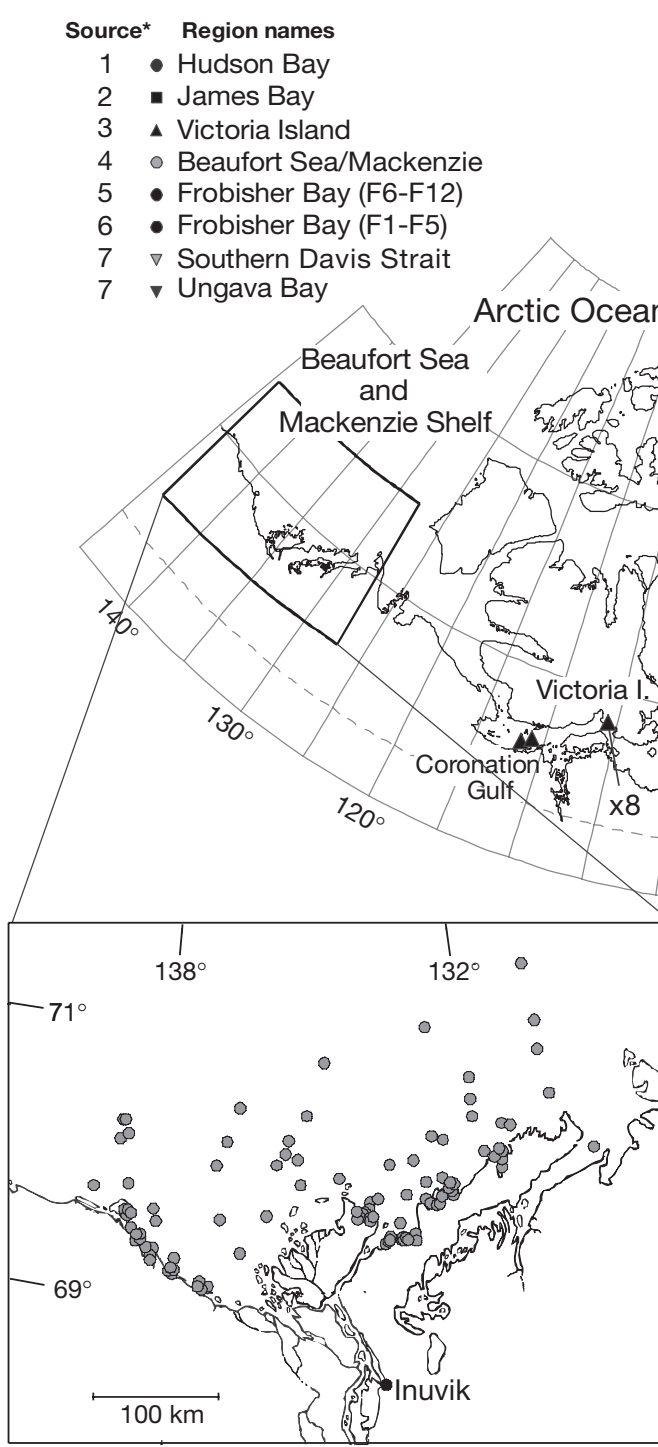

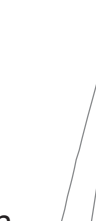

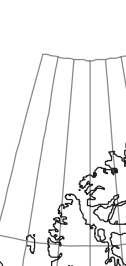

$85^{\circ}$
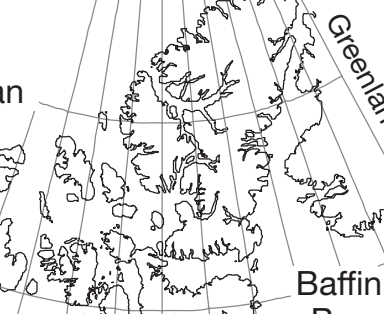

Baffin
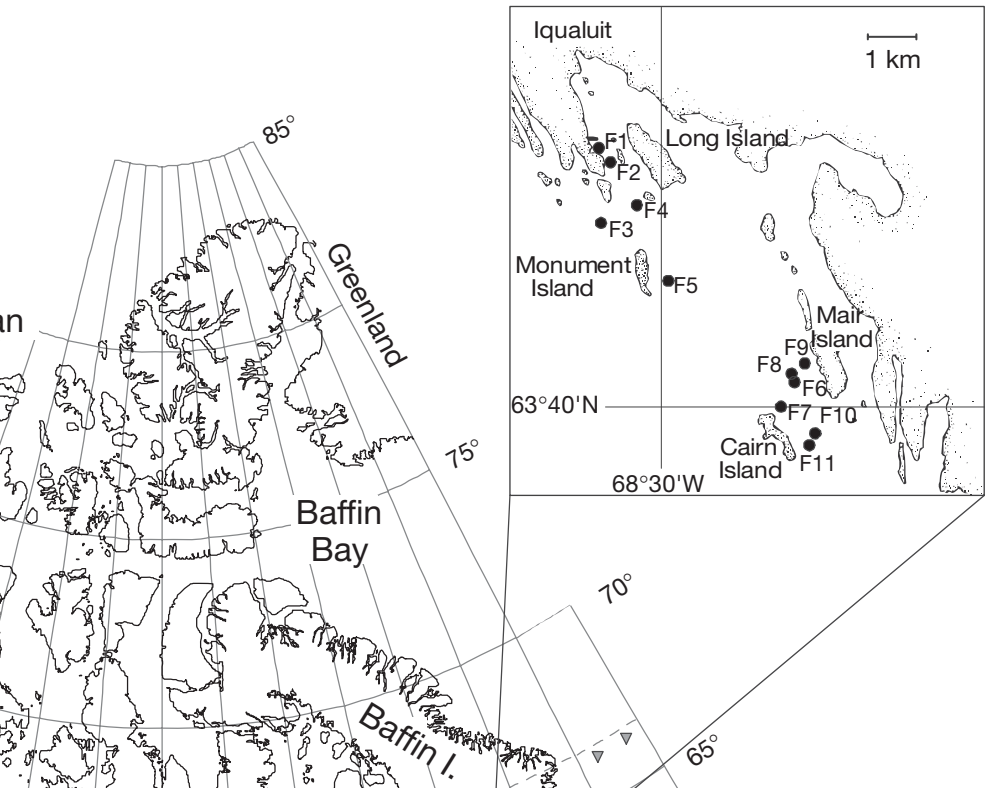
salinity, and for some stations the chemical properties of the sediment) were examined. For $12 \%$ of the stations, bottom temperatures were obtained from the nearest station during the same time period.

Based on the method used by the different research groups, all samples were sieved through a $500 \mu \mathrm{m}$ mesh sieve, and macrofauna sorted under a stereomicroscope (method described in detail in the particular references used). Taxonomic names were checked and updated (e.g. for old or sister names) using data retrieved from the Integrated Taxonomic Information System on-line database (www.itis.gov) and other general invertebrate references (e.g. Barnes 1987, Pechenik 1991). Most data came from the same research groups (Arctic Biological Station, Department of Fisheries and Oceans Canada: sources 1 to 6 , see Table 1), which ensured consistency in the taxonomic resolution and identification of organisms.

Following Gray's (2000) terminology, the $\alpha$ diversity $\left(S R_{\mathrm{S}}\right)$ measurement represents species richness (S: number of species) from samples from a defined area and was associated with each site from a given 'larger area' or region; $\gamma$ diversity $\left(S R_{\mathrm{L}}\right)$, which includes a variety of habitats and assemblages, is represented by the total number of species from each region. Total species richness $\left(S R_{\mathrm{T}}\right)$ represents the total number of species included in this study. The turnover ( $\beta$ ) diversity, which describes how species similarity changes along an environmental gradient or between habitats, was assessed using Whittaker's $\beta_{\mathrm{W}}$ diversity $\left(\beta_{\mathrm{W}}=S R_{\mathrm{L}} / S R_{\mathrm{S}}\right)$. Bray-Curtis-similarity (\%) between all pair-wise combinations of sites from a given region was also used as a measure of turnover diversity (Mumby 2001, Thrush et al. 2001, Ellingsen \& Gray 2002) and is considered to be a good measure (Magurran 2004).

Data analysis. One-way analysis of covariance (ANCOVA; GLM and MIXED procedure, SAS 1999) was used to compare total density (ind. $\mathrm{m}^{-2}$ ), species richness or $\alpha$ diversity ( $S R_{\mathrm{S}}$ : number of species), Shannon-Wiener's diversity index $\left(H^{\prime}, \log _{\mathrm{e}}\right)$, and Pielou's evenness index $\left(J^{\prime}: H^{\prime} / \log S R_{\mathrm{S}}\right)$ among regions using water depth and bottom temperature as covariates. Average taxonomic distinctness $\left(\Delta^{+}\right)$and variation in taxonomic distinctness $\left(\Lambda^{+}\right)$, which estimate the average distance between 2 randomly chosen organisms through Linnean taxonomy, were determined with presence/absence data (DIVERSE analyses, PRIMER v5, Clarke \& Gorley 2001). These 2 measures are more relevant than the univariate measures mentioned below when assessing biodiversity from an unequal sampling effort, and provide valuable tools to compare historical data and/or meta-analyses over large spatial and temporal scales (Clarke \& Warwick 1998, 2001a, b). Tukey-Kramer multiple comparisons tests (SAS 1999) were carried out to determine mean differences among regions. Multiple regression analyses were used to link abiotic parameters to biotic variables. Step-wise multiple regressions (REG procedure, SAS 1999) were used to examine the relationships between dependent variables (total density, $S R_{\mathrm{S}}, H^{\prime}$ and $J^{\prime}$ ) and environmental conditions (temperature, salinity, water depth of sampling site, percentage of sand, silt and clay, and chemical characteristics of the sediment). Robustness of the regression models was evaluated by the leave-one-out cross-validation method (Stone 1974). This test systematically excludes 1 data point at a time and predicts its value using the regression model adjusted to the remaining data set. Normality was verified using Shapiro-Wilk's test (Zar 1999), and homoscedasticity was confirmed by graphical examination of residuals (Scherrer 1984, Montgomery 1991).

Methods of Clarke \& Warwick $(1994,2001$ a) using the PRIMER software (Clarke \& Gorley 2001) were used to detect spatial and temporal patterns in community structure. Before similarity comparisons among stations were conducted, we discarded species or taxonomic groups $(\mathrm{n}=315)$ associated with only 1 station as suggested by the authors. Faunal data were 4 th-root transformed prior to analyses to avoid the strong impact of common species, as recommended by Field et al. (1982). Differences in the structure of benthic assemblages among various regions within the Canadian Arctic were identified by non-metric multidimensional scaling (nMDS) ordination using the Bray-Curtis similarity measure (Bray \& Curtis 1957, Clarke 1993). Analyses of similarity (ANOSIM) tested the significance of differences among regions or groups of samples from a given region.

For regions where environmental variables were available (i.e. Beaufort Sea and MacKenzie Shelf, James Bay and Frobisher Bay), Spearman's rank correlations were used to examine relationships with ordination scores (BIO-ENV analyses, PRIMER). For this analysis, biotic and abiotic matrices were constructed using Bray-Curtis dissimilarity (4th-root transformed) and Euclidean distances respectively (see Clarke \& Ainsworth 1993, Clarke \& Warwick 2001a). Spearman's rank correlations were also used to examine the relationship between ordination scores and the taxa that best explained the observed pattern of community similarity. The contribution of each species (or higher taxonomic level) to the average Bray-Curtis dissimilarity between regions (or groups of sites) was assessed (SIMPER analyses, PRIMER). A significance threshold of $\alpha=0.05$ was adopted for all statistical tests.

\section{RESULTS}

A total $\left(S R_{\mathrm{T}}\right)$ of 947 species or taxonomic groups (within 229 different families, 68 orders, 29 classes and 15 phyla) were present at the stations examined in this 
study ( $\mathrm{n}=219$ ). Arthropoda and Annelida represented 45 and $31 \%$, respectively, of all species included in our database. Benthic composition varied from west to east across the study region, with an average composition of $37 \%$ Annelida and $31 \%$ Arthropoda (Fig. 2). With the exception of DS, we observed a greater proportion of Arthropoda in the eastern regions (UB and F) than in the central regions ( $\mathrm{V}, \mathrm{HB}$ and JB), where Annelida dominated.

\section{Density, $\alpha\left(S R_{\mathrm{S}}\right), \gamma\left(S R_{\mathrm{L}}\right)$ and turnover $(\beta)$ diversities, $H^{\prime}$ and $J^{\prime}$ indices and taxonomic distinctness}

The use of covariates did not relate to densities, and only bottom temperature was retained in the ANCOVA for $J$ (see Table 2). All univariate variables revealed differences among regions (Table 2, Fig. 3). The largest densities of organisms were observed in $\mathrm{F}$, probably due to the large number of Nemata (Nematoda) (up to $9.4 \times 10^{3}$ ind. $\mathrm{m}^{-2}$ ), whereas the lowest densities were observed in JB (Fig. 3a). High species richness (or $\alpha$ diversity: $S R_{\mathrm{S}}$ ) was observed in the eastern regions (UB, F and DS) and in the $\mathrm{V}$ region, whereas low values of $S R_{\mathrm{S}}$ were observed in $\mathrm{HB}$ (Fig. $3 \mathrm{~b}$ ). The BM region exhibited low diversity $\left(H^{\prime}\right)$, whereas high diversity was observed in the $\mathrm{V}$ and $\mathrm{F}$ regions. All other regions exhibited intermediate values (Fig. 3c).

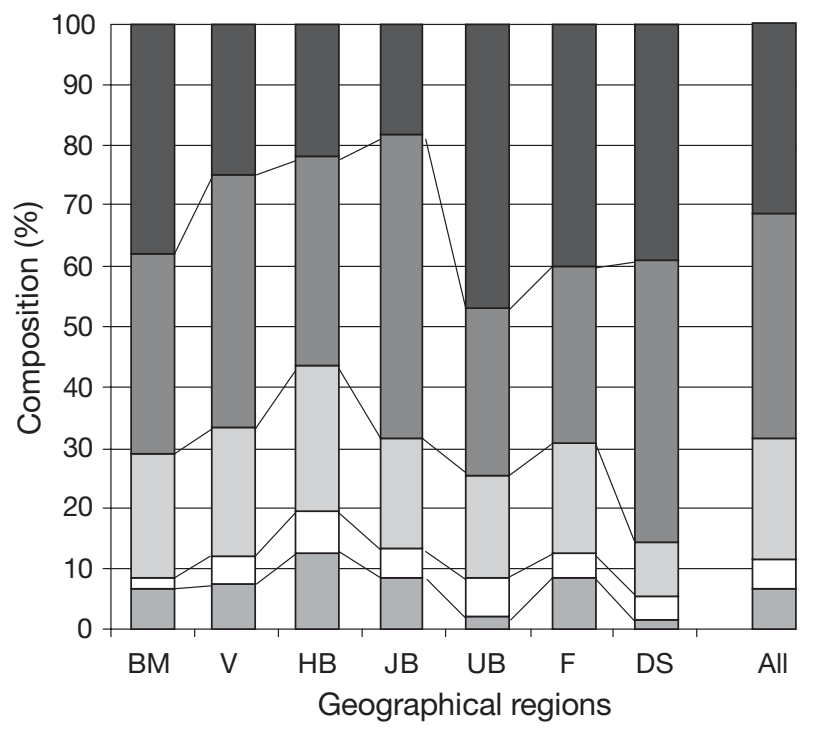

$\square$ Arthropoda $\square$ Annelida $\square$ Mollusca $\square$ Echinodermata $\square$ Others

Fig. 2. Composition of macrozoobenthic phyla from various regions in the Canadian Arctic. From west to east, BM: Beaufort Sea and Mackenzie Shelf; V: Victoria Island; HB: Hudson Bay; JB: James Bay; UB: Ungava Bay; F: Frobisher Bay; DS: Southern Davis Strait; 'Others' included Brachiopoda, Chordata, Cnidaria, Echiura, Ectoprocta, Nemata (Nematoda), Nemertea, Platyhelminthes, Porifera, Priapula, and Sipuncula
Table 2. Summary of ANOVA/ANCOVA with bottom temperature and water depth as covariates, showing effects of: (a) density; (b) species richness $\left(S R_{\mathrm{S}}\right) ;$ (c) diversity $\left(H^{\prime}\right)$; (d) evenness $\left(J^{\prime}\right)$; (e) average taxonomic distinctness $\left(\Delta^{+}\right)$; and (f) variation in taxonomic distinctness $\left(\Lambda^{+}\right)$. Density and species richness were log transformed; depth was square-root transformed to normalize and homogenize the data

\begin{tabular}{|c|c|c|c|c|}
\hline Source of variation & df & MS & $F$ & $\mathrm{p}$ \\
\hline \multicolumn{5}{|l|}{ (a) Density } \\
\hline Regions & 5 & 6.59 & 15.44 & $<0.0001$ \\
\hline Error & 165 & 0.43 & & \\
\hline \multicolumn{5}{|c|}{ (b) Species richness $\left(S R_{\mathrm{S}}\right)$} \\
\hline Bottom temperature & 1 & 2.78 & 20.61 & $<0.0001$ \\
\hline Water depth & 1 & 0.82 & 6.07 & 0.0145 \\
\hline Regions & 6 & 8.68 & 64.19 & $<0.0001$ \\
\hline Error & 227 & 0.14 & & \\
\hline \multicolumn{5}{|l|}{ (c) Diversity $\left(H^{\prime}\right)$} \\
\hline Bottom temperature & 1 & 7.80 & 17.18 & $<0.0001$ \\
\hline Water depth & 1 & 3.90 & 8.59 & 0.0039 \\
\hline Regions & 5 & 2.66 & 5.86 & $<0.0001$ \\
\hline Error & 165 & 0.45 & & \\
\hline \multicolumn{5}{|l|}{ (d) Evenness $\left(J^{\prime}\right)$} \\
\hline Bottom temperature & 1 & 0.12 & 5.40 & 0.0214 \\
\hline Regions & 5 & 0.11 & 5.23 & 0.0002 \\
\hline Error & 160 & 0.02 & & \\
\hline \multicolumn{5}{|l|}{ (e) Average $\Delta^{+}$} \\
\hline Regions & 6 & 1652 & 3.55 & 0.0022 \\
\hline Error & 229 & 465 & & \\
\hline \multicolumn{5}{|c|}{ (f) Variation in taxonomic distinctness $\left(\Lambda^{+}\right)$} \\
\hline Regions & 6 & 308873 & 7.07 & $<0.0001$ \\
\hline Error & 229 & 43686 & & \\
\hline
\end{tabular}

High evenness $\left(J^{\prime}\right)$ was observed in the JB and DS regions, whereas lower values were seen in the F and UB regions (Fig. 3d). Although the BM region exhibited low diversity (Fig. 3c) and moderate $S R_{\mathrm{S}}$ (Fig. 3b), a high average taxonomic distinctness $\left(\Delta^{+}\right)$was observed in this region (Fig. 3e). Low values of $\Delta^{+}$were observed in the HB region. Low values of variation in taxonomic distinctness $\left(\Lambda^{+}\right)$were found in the BM and HB regions, whereas high values were observed in the eastern regions (UB, F, and DS; Fig. 3f). The highest $\gamma$ diversity $\left(S R_{\mathrm{L}}\right)$ was observed in $\mathrm{F}$, whereas the lowest was found in JB (Table 3). High turnover ( $\beta$ ) diversity values were observed in $\mathrm{HB}$ (i.e. high $\beta_{\mathrm{W}}$ and low pair-wise BrayCurtis similarities), whereas low values were found in the $\mathrm{V}$ and eastern regions (F, UB and DS; Table 3).

Multiple linear regression models explained up to $31 \%$ of total macroinvertebrate density variance, up to $58 \%$ of species richness $\left(S R_{\mathrm{S}}\right)$ variance, $43 \%$ of diversity $\left(H^{\prime}\right)$ variance, and $20 \%$ of evenness $\left(J^{\prime}\right)$ variance (Table 4). Variance in total macroinvertebrate density was best explained by bottom temperature variance $(12 \%)$. Species richness and diversity variance were best explained by variance in salinity (55 and $43 \%$ respectively). The evenness variance was equally 

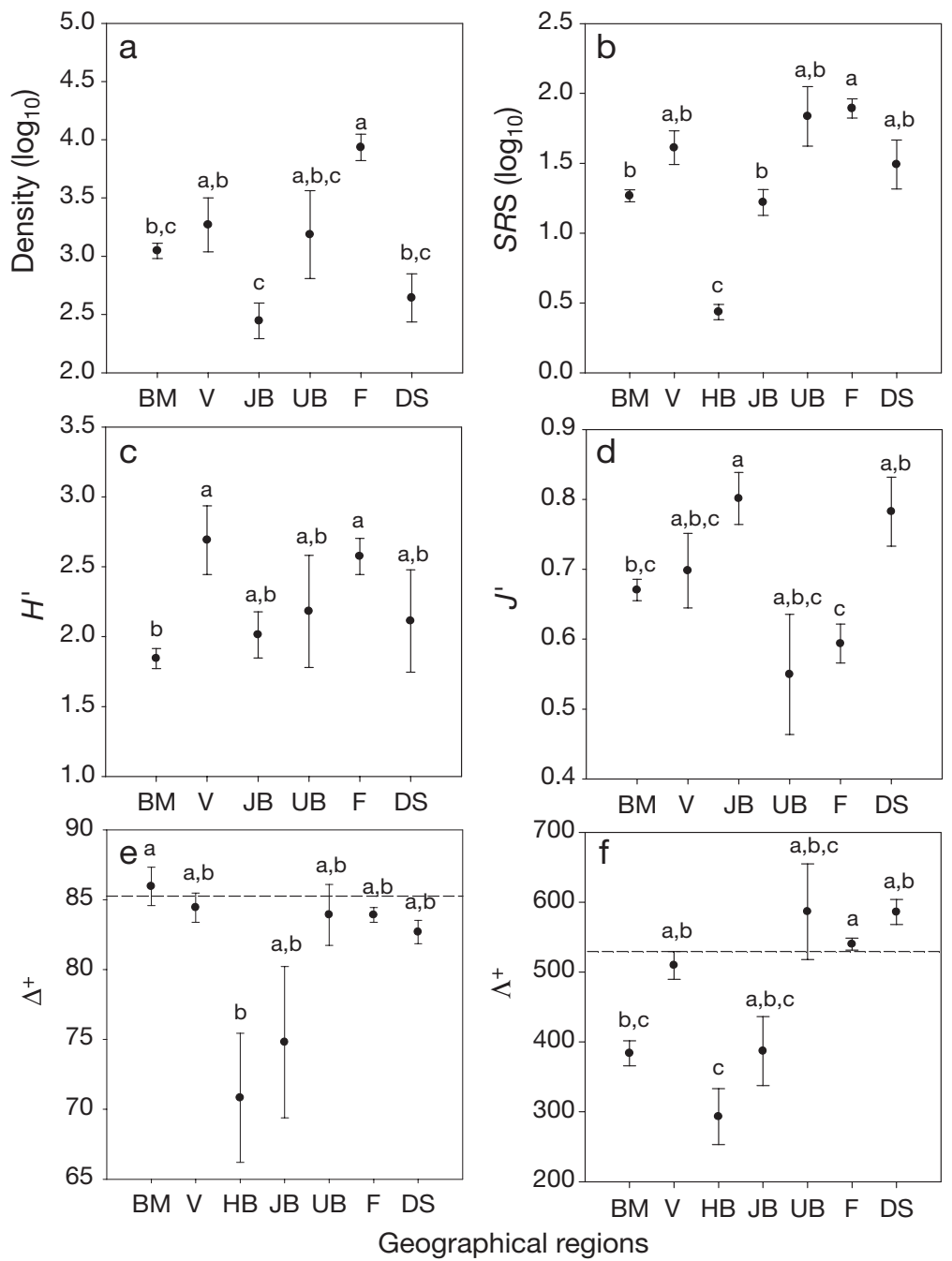

Fig. 3. Least-squared mean of: (a) density (ind. $\mathrm{m}^{-2}$ ); (b) species richness $\left(S R_{\mathrm{S}}\right)_{;}$(c) Shannon-Wiener's diversity index $\left(H^{\prime}\right)_{;}$(d) Pielou's evenness index $\left(J^{\prime}\right)_{i}(\mathrm{e})$ average taxonomic distinctness $\left(\Delta^{+}\right)$(presence/absence data); and (f) variation in taxonomic distinctness $\left(\Lambda^{+}\right)$(presence/absence data) for each geographical region, see Fig. 2 for region abbreviations. Dashed line in (e) and (f) indicates values of $\Delta^{+}$and $\Lambda^{+}$from the master list of 947 taxa. Note: for $\mathrm{HB}$, only $S R_{\mathrm{S}}, \Delta^{+}$and $\Lambda^{+}$were estimated due to the nature of the data (species list). Error bars: $\pm S E$; different letters $(a, b, c)$ above points indicate significant differences $(p<0.05)$ explained by variance in the percentage of silt and in the nitrate and ammonia content of the sediment. When only the chemical characteristics of the sediment were included in models (see second models in Table 4, where salinity, temperature, water depth and percentage of silt were not included [NI]), potassium and ammonia content were important variables, accounting for the remaining variance in total density, species richness and diversity values.

\section{Benthic assemblages}

Results revealed that $\mathrm{HB}, \mathrm{JB}$ and $\mathrm{BM}$ had very peculiar species compositions with a wide spectrum of assemblages (Fig. 4). The species composition of the JB region was more similar to that of the $\mathrm{BM}$ communities than to that of $\mathrm{HB}$, which is closer spatially. However, ANOSIM analyses (Table 5) revealed that the assemblages of the $\mathrm{HB}$ and $\mathrm{JB}$ regions were dissimilar only at the species level but not at the order or other higher taxonomic levels, whereas the assemblages of HB and BM were dissimilar at all levels of taxonomic resolution (Table 5). We did not observe any differences in presence/ absence data between JB and BM at any level of taxonomic resolution. No major differences were observed in the nMDS plots (excluding HB sites, for which only species lists were available) (compare Fig. 4b with Fig. 4a). F stations (O) were restricted to a small area in all nMDS plots (Fig. 4), and ANOSIM indicated that the $\mathrm{F}$ region had a distinct benthic community composition relative to all other

Table 3. $\gamma$ diversity $\left(S R_{\mathrm{L}}\right)$ and measures of turnover $(\beta)$ diversity for each region using mean Whittaker's $\left(\beta_{\mathrm{W}}\right)$ diversity and mean Bray-Curtis similarity (\%) between all pair-wise comparisons of sites. CI: $95 \%$ confidence intervals

\begin{tabular}{|c|c|c|c|}
\hline \multirow[b]{3}{*}{ Region } & \multirow{3}{*}{$\begin{array}{c}\gamma \text { diversity } \\
S R_{\mathrm{L}}\end{array}$} & \multicolumn{2}{|c|}{ Turnover $(\beta)$ diversity } \\
\hline & & $\beta_{\mathrm{W}}\left(S R_{\mathrm{L}} / S R_{\mathrm{S}}\right)$ & Bray-Curtis similarity (\%) \\
\hline & & Mean \pm CI & Mean \pm CI \\
\hline Beaufort Sea and Mackenzie Shelf (BM) & 327 & $42.2 \pm 11.1$ & $17.8 \pm 0.5$ \\
\hline Victoria Island (V) & 167 & $3.9 \pm 1.2$ & $38.9 \pm 4.3$ \\
\hline Hudson Bay (HB) & 167 & $62.4 \pm 13.8$ & $6.2 \pm 0.6$ \\
\hline James Bay (JB) & 104 & $18.2 \pm 11.6$ & $18.4 \pm 2.3$ \\
\hline Frobisher Bay $(\mathrm{F})$ & 434 & $5.7 \pm 1.4$ & $47.8 \pm 3.9$ \\
\hline Ungava Bay (UB) & 232 & $2.1 \pm 0.8$ & $36.6 \pm 5.0$ \\
\hline Southern Davis Strait (DS) & 312 & $5.9 \pm 2.4$ & $29.4 \pm 3.3$ \\
\hline Total of taxa from all regions $\left(=S R_{\mathrm{T}}\right)$ & 947 & & \\
\hline
\end{tabular}




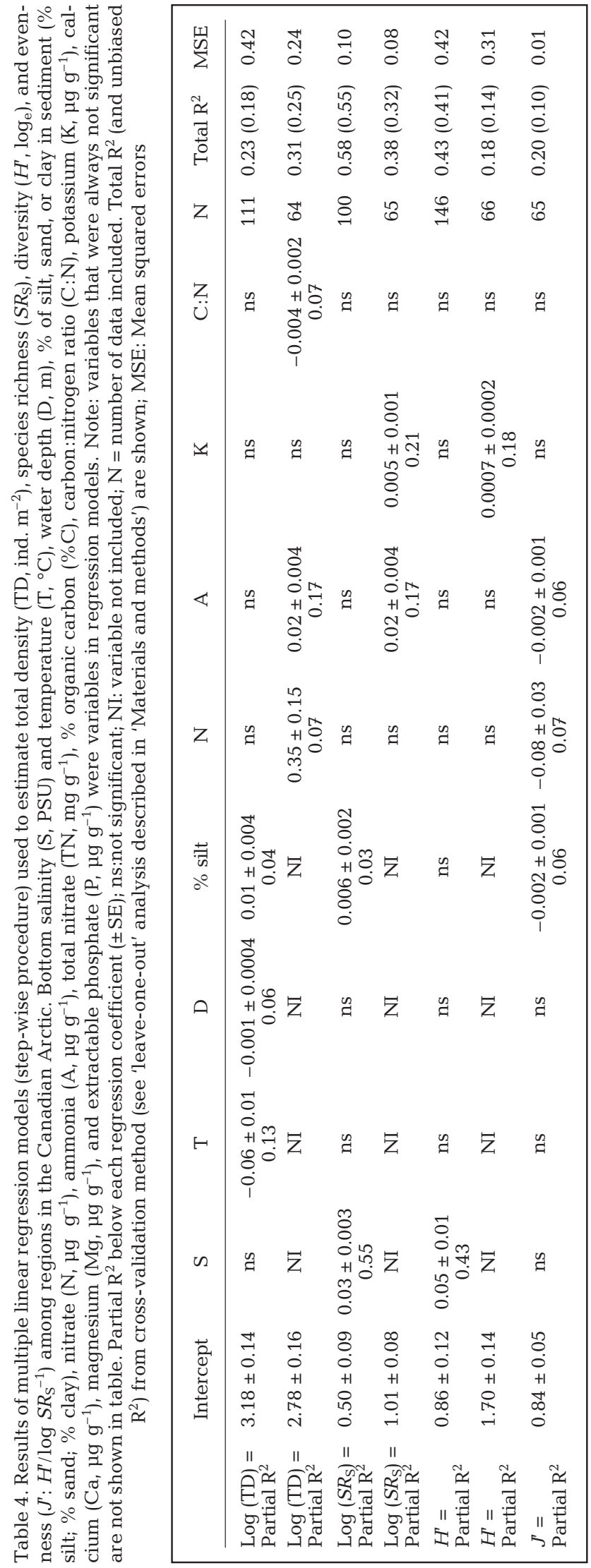

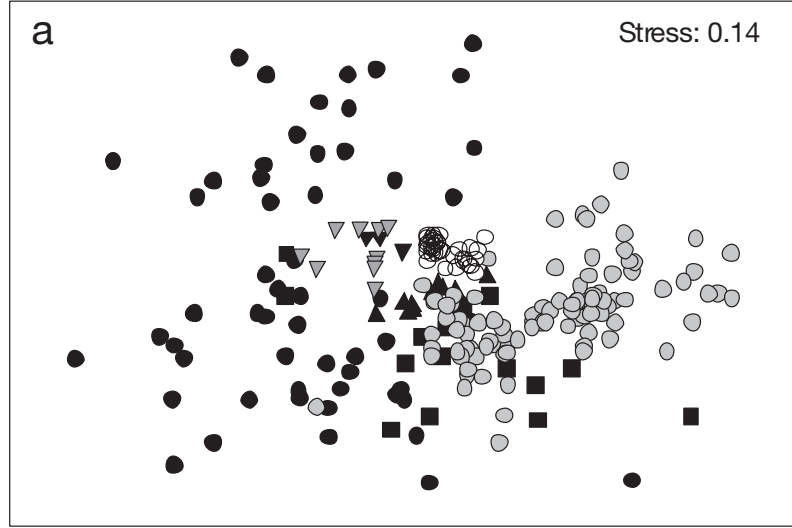

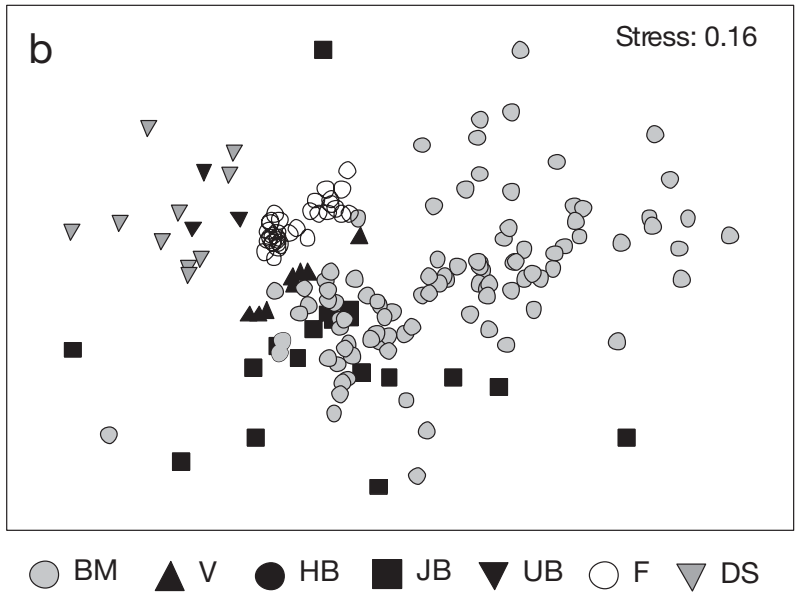

Fig. 4. Non-metric multidimensional scaling (nMDS) ordinations of macrofaunal assemblages from the 7 study regions according to: (a) presence/absence transformation; and (b) 4th-root transformation prior to calculation of Bray-Curtis similarities. Note: no data on organism density was available from $\mathrm{HB}$; thus, $\mathrm{HB}$ sites were included only in the presence/absence transformation plot. See Fig. 2 for region abbreviations

stations at all levels of taxonomic resolution (except Order level) (Table 5; other results not shown).

Among those stations for which density data were available, we observed that the BM region was dissimilar to all other regions at the species level but only to the JB and F regions at higher taxonomic levels (Fig. 3, Table 5). The F region was distinct from most others at all levels of taxonomic resolution (Species, Order, Class, and Phyla level). The benthic community at V was generally distinct from the most eastern regions (UB, F, and DS).

Generally, Annelida contributed most of the similarity within regions. This phylum explained 41.8, 30.8, 49.3, 27, and $31.5 \%$ of similarities (Bray-Curtis, 4throot transformation) among sites for the $\mathrm{BM}, \mathrm{V}, \mathrm{JB}, \mathrm{F}$, and DS regions respectively. Indeed, Annelida were mainly responsible for the dissimilarity among regions, 
Table 5. R-statistics results of 1-way ANOSIM based on similarity matrices derived from presence/absence- and 4th-root transformed densities of different taxonomic levels among regions. BM: Beaufort Sea and Mackenzie Shelf; V: Victoria Island; HB: Hudson Bay; JB: James Bay; UB: Ungava Bay; F: Frobisher Bay; DS: Southern Davis Strait. Pair-wise tests between regions; results with $\mathrm{p}<5 \%$ in bold

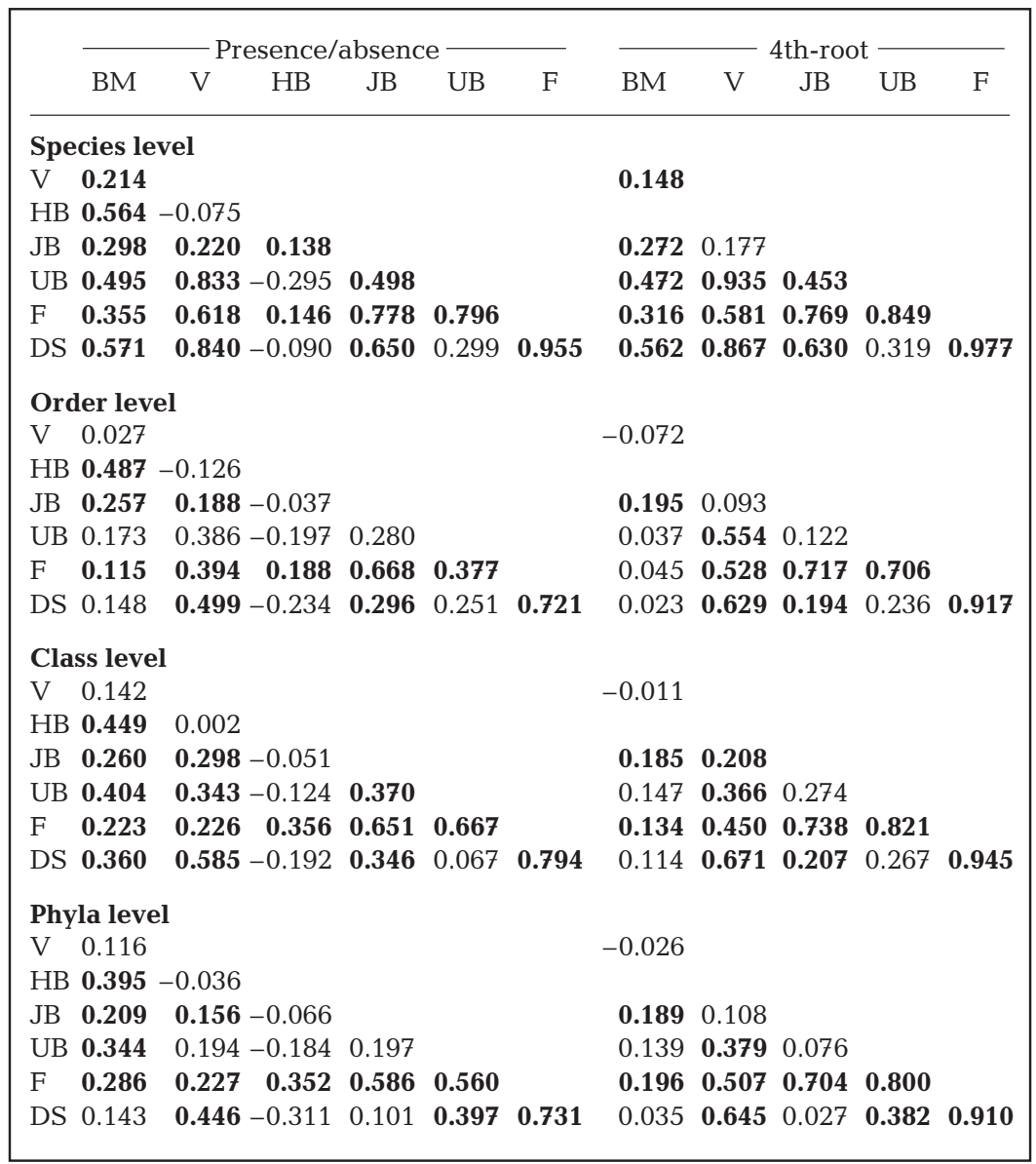

60; \% clay: $51 ; 1$ to $84 ; \%$ sand: $16 ; 1$ to 97 ). Salinity and bottom temperature best explained the pattern of macrobenthic assemblages (Table 6). Salinity accounted for as much variance alone as when combined with temperature. An analysis of a subset of stations for which physical (depth, temperature and salinity) and oceanographic data and chemical (nitrate; ammonia; total nitrate; \% organic carbon; carbon:nitrate ratio; potassium; calcium; manganese; extractable phosphate) properties of sediments were also available ( $\mathrm{n}=$ 61; results not shown) indicated that the addition of chemical variables did not improve the rank correlation $\left(\rho_{\mathrm{s}}\right)$ between biotic and abiotic similarity matrices. Nevertheless, variables such as the nitrogen, total nitrogen and \% organic carbon content were the most important of the chemical sediment properties as they were more often selected in the best variable combinations together with salinity and temperature.

\section{Temporal variations in benthic assemblages}

Four sampling time series from $\mathrm{F}$ were available. Each series exhibited a cloud size (or extent) that could be with an average contribution of $23 \%$ in all pair-wise comparisons (Arthropoda: 16\%; Mollusca: 12.4\%; Echinodermata: $11.7 \%$ ). Nemata explained 18 to $24 \%$ of the dissimilarity between the F region and all other regions, and Echinodermata explained 10 to $31 \%$ of the dissimilarity between the UB region and all other regions.

\section{Influence of environmental variables on benthic assemblages}

In regions where environmental data were available (i.e. BM, JB and F), sites were distributed within a wide range of environmental conditions: salinity (median: $21 \mathrm{PSU}_{\text {; range }} 0.1$ to $35 \mathrm{PSU}$ ), bottom temperature (median: $4^{\circ} \mathrm{C}_{i}-1.8$ to $17^{\circ} \mathrm{C}$ ), depth (median: $12 \mathrm{~m} ; 1$ to $441 \mathrm{~m}$ ), and sediment texture (\% silt: median: $25 ; 1$ to
Table 6. Macrobenthos from Beaufort Sea and MacKenzie Shelf (BM), James Bay (JB) and Frobisher Bay (F) $(n=101)$. Combinations of environmental variables, taken $k$ at a time, giving largest rank correlation $\rho_{\mathrm{s}}$ between biotic and abiotic similarity matrices; bold indicates best combination overall. $\mathrm{S}$ : bottom salinity (PSU); $\mathrm{T}$ : bottom temperature $\left({ }^{\circ} \mathrm{C}\right)$; D: depth (m); \%Silt, \%Clay, and \%Sand: \% of silt, clay or sand in sediment

\begin{tabular}{|c|c|c|c|c|}
\hline$k$ & \multicolumn{4}{|c|}{ Best variable combinations $\left(\rho_{s}\right)$} \\
\hline 1 & $\begin{array}{l}\mathrm{S} \\
(0.53)\end{array}$ & $\begin{array}{l}\mathrm{T} \\
(0.44)\end{array}$ & $\begin{array}{l}\mathrm{D} \\
(0.18)\end{array}$ & \\
\hline 2 & $\begin{array}{l}\mathrm{T}, \mathrm{S} \\
(0.53)\end{array}$ & $\begin{array}{l}\text { S, \% Silt } \\
(0.36)\end{array}$ & $\begin{array}{l}\text { S, \% Sand } \\
(0.32)\end{array}$ & $\begin{array}{l}\text { S, \%Clay } \\
(0.29)\end{array}$ \\
\hline 3 & $\begin{array}{l}\text { T, S, \% Silt } \\
(0.38)\end{array}$ & $\begin{array}{l}\mathrm{T}, \mathrm{S}, \% \text { Sand } \\
(0.32)\end{array}$ & $\begin{array}{l}\mathrm{T}, \mathrm{S}, \% \text { Clay } \\
(0.31)\end{array}$ & \\
\hline 4 & $\begin{array}{l}\text { T, S, } \\
\% \text { Sand, \% Si } \\
(0.29)\end{array}$ & & & \\
\hline
\end{tabular}




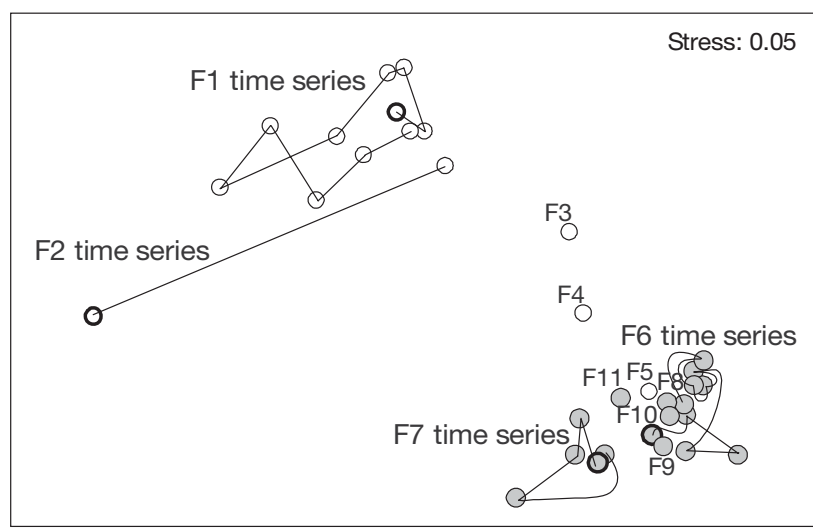

Fig. 5. nMDS ordinations of macrofaunal assemblages from stations in Frobisher Bay. Open circles (F1-F5): northern stations; gray circles (F6-F11): southern. O: starting sample date for stations when time series were available. Dates for the time series: F1: Jul. 1969 to Aug. 1976; F2: Aug. 1973 and Aug. 1976; F6: Jul. 1968 to Aug. 1970; F7: Dec. 1967 to Aug. 1968. Data were 4th-root transformed prior to calculation of Bray-Curtis similarities

linked with its own total (Fig. 5). No correlation ( $\mathrm{p}=$ $0.66, \mathrm{n}=21$ when station F2 is not considered) was observed between the Bray-Curtis similarity index of 2 successive dates and the amount of time (mo) separating these sampling dates. The nMDS plots showed that the temporal variability of a given station might be as strong as the spatial variability among stations from $F$. We observed a difference in benthic assemblage between 2 subregions in F: the northern stations in the vicinity of Long Island and the southern stations in the vicinity of Cairn Island (Fig. 1). The phylum Nemata and the taxa Philomedes brenda (Arthropoda), subclass Oligochaeta, and Heteromastus sp. (Annelida) contributed most to the dissimilarity (untransformed) in benthic assemblages between the 2 subregions (with 15 and 18 samples respectively), and contributed $15,10,8$ and $6 \%$ (respectively) to total dissimilarity.

\section{Effect of the taxonomic resolution and data transformation}

The decrease in the level of taxonomic resolution from species to phylum had a moderate effect on nMDS plots (results not shown) and ANOSIM results. Overall, the reduction in the level of resolution reduced dissimilarity among regions (Table 5). The reduction in taxonomic resolution changed the ANOSIM results of the BM region (different from all other regions at Species level, but only from the JB and F regions at higher taxonomic resolution; see Table 4). The effect was less obvious in the F region, where ben- thic assemblages remained distinct from those of all other regions at all levels of resolution (see Table 5). Data transformation had no notable effect on nMDS plots (not shown) or ANOSIM (partly shown in Table 5).

\section{DISCUSSION}

This study revealed particular spatial patterns among Canadian Arctic regions. Our results revealed temporal and spatial trends in biodiversity measurements and assemblages at both local and continental scales.

\section{Biodiversity comparison among regions}

Various measurements related to biodiversity $\left(S R_{\mathrm{S}}\right.$, $S R_{\mathrm{L}}, H^{\prime}, J^{\prime}, \Delta^{+}$, and $\Lambda^{+}$) revealed large differences among regions. Similar differences were previously reported for Arctic and Antarctic asteroids (Piepenburg et al. 1997a). One of the most fundamental ecological patterns recognized is the decrease in biodiversity with increasing latitude (e.g. Rex et al. 1993, Macpherson 2002). However, recent studies have failed to find a strong link between biodiversity and latitudinal gradient (Ellingsen \& Gray 2002, Willig et al. 2003): indeed, such exceptions were observed in benthos from high latitude and temperate regions in the northern (e.g. Kendall 1996, Gray 2001) and southern (Piepenburg et al. 2002) hemispheres. Our data supported these latter observations, because we did not observe a decrease in either species richness or diversity across regions that span $15^{\circ}$ of latitude $\left(55^{\circ}\right.$ to $\left.70^{\circ} \mathrm{N}\right)$. However, this should be addressed in further detail (e.g. using standardized sampling along transects in common water mass).

When a meta-analysis is conducted, dealing with regions of variable size is common. Strictly, comparisons of diversity measurements from different regions of variable size and/or habitat may be hazardous (Magurran 2004, Piepenburg 2005). However, the use of data from standardized sampling methods, various scaled biodiversity measurements $(\alpha$ and $\gamma$ ), and indices that are independent of sample size $\left(\Delta^{+}\right.$and $\left.\Lambda^{+}\right)$ combined with turnover $(\beta)$ diversity may give a more representative picture of biodiversity. Turnover diversity reflects biotic change or species replacement and is usually associated with habitat diversity. Unfortunately, bottom habitat description remains difficult in the Arctic, and we do not have precise habitat information at a fine-scale resolution from every region that can enhance our knowledge of local biodiversity (Teixido et al. 2002, Hewitt et al. 2005). High values of turnover diversity observed in the HB and BM regions, 
from both Whittaker $\beta_{\mathrm{W}}$ and Bray-Curtis similarities, may provide information on the number of habitats present in these regions, and it was not surprising that values also appeared to be linked to the size of the regions considered (excluding the DS region).

Differences in biodiversity among the Canadian Artic regions may be linked to both biotic and abiotic factors. The benthic compartment can be seen as an integrator of environmental conditions and overlying water column processes. Piepenburg et al. (1997a) noted that the relatively high taxonomic diversities of asteroids in Greenland waters may be governed by depth and historical stabilities. Intense sea-ice scouring occurs regularly in the BM region (see Blasco et al. 1998, Hill et al. 2001). The associated disturbance of the seafloor via processes linked to the 'intermediate disturbance hypothesis' (sensu Connell 1978, Huston 1979) may help to maintain macrobenthic diversity in this region (Barnes 1999, Gutt 2000, Conlan \& Kvitek 2005). The BM region, which exhibited moderate species richness (or $\alpha$ diversity, $S R_{\mathrm{S}}$ ) and a relatively low diversity $\left(H^{\prime}\right)$, had the highest taxonomic distinctness values, which increased its biodiversity profile. This situation may reflect the combined effects (at different spatial and temporal scales) of recurrent ice-scour local disturbances and the seasonal freshwater input from the Mackenzie River, which strongly affects the salinity and temperature conditions across the shelf.

The evolutionary history of environmental conditions can be considered an important factor determining faunal distribution. Indeed, the earliest post-glacial records of molluscs in the Canadian Arctic Archipelagos were identified in the BM region (Dyke et al. 1996a), which indicate early migration following Late Pleistocene deglaciation of this region. Variations in the composition of benthic mollusc assemblages inhabiting the Canadian Arctic have been linked with changes in physical oceanography associated with phases of glacier retreat (e.g. Baffin fjords, Syvitski et al. 1989; central Canadian Arctic, Gordillo \& Aitken 2001). The relatively low and moderate values in diversity $\left(H^{\prime}\right)$ and species richness $\left(S R_{\mathrm{S}}\right)$ in the BM region in comparison with eastern regions (UB, F and DS) might be related to a west-to-east gradient in primary production. This trend has been recognized for quite some time (Curtis 1975). Thomson (1982) invoked increasing primary production and nutrient levels from the central to the eastern Canadian Arctic in order to account for the increase in biomass in nearshore $(5$ to $50 \mathrm{~m}$ depth) benthic communities (see also Carey 1991). The large densities observed in F may be linked to the high primary production level measured in that bay (40 to $70 \mathrm{~g} \mathrm{C} \mathrm{m}^{-2} \mathrm{yr}^{-1}$, Grainger 1975; $311 \mathrm{mg} \mathrm{C} \mathrm{m}^{-2} \mathrm{~d}^{-1}$, Atkinson \& Wacasey 1987). Food availability has been recognized as an important factor influencing species composition and abundance in benthic assemblages in other polar environments (e.g. Arctic continental shelves, Grebmeier \& Barry 1991; polynya, Piepenburg et al. 1997b). The BM region is affected by the proximity of the Mackenzie River, which is by far the most sediment-rich river discharging into the Arctic Ocean (Carmack \& MacDonald 2002). Variations in salinity and the presence of unproductive cold Arctic water masses were suggested to account for the low species richness in the $\mathrm{BM}$ region in comparison with other arctic regions (Curtis 1975).

In contrast to the BM region, the deepest sites in DS (mean: $558 \mathrm{~m}$ ) exhibited high species richness and low turnover diversity, indicating homogenous habitat among sites. Many studies have demonstrated that greater species richness is observed on the continental slope rather than on the continental shelf. These observations were explained by means of the stability time hypothesis (see Sanders 1969, Sanders \& Hessler 1969) related to the mode of reproduction (Sanders 1977) or by life-history strategy (Flach \& de Bruin 1999). In the DS region, where sites were located on the continental slope, both annelids (often $r$-strategists) and arthropods (mainly crustaceans with broodcare; $K$-strategists) were abundant. They may compete for food, and niche partitioning could account for the high degree of observed species richness (see 'Discussion' in Flach \& de Bruin 1999). This hypothesis should be addressed more precisely in the future. The observed low biodiversity $\left(S R_{\mathrm{S}}, H^{\prime}, J^{\prime}, \Delta^{+}\right.$, and $\left.\Lambda^{+}\right)$in the HB and JB regions is difficult to explain. These results are reflected by the low mollusc diversity observed in the glacial Tyrrell Sea (Dyke et al. 1996a). The central Arctic region was the last area to be deglaciated (-8.5 ka BP, e.g. Dyke et al. 1996b); hence, there has been a relatively shorter time period for migrants to colonize benthic environments, which may have contributed to the relatively poor diversity indices. Again, this hypothesis should be investigated more precisely using, for example, forms in the Quaternary fossil record (e.g. Gordillo \& Aitken 2000).

\section{Effects of abiotic factors on benthic assemblages}

Our results indicate that salinity and temperature variables best describe the observed patterns in the structure of benthic assemblages. The regions where environmental data were available for this study contain a number of stations in close proximity to the mouths of large rivers: the MacKenzie River in the BM region, and La Grande Rivière in the JB region. These stations are characterized by a wider range of temperature and salinity than the other shelf environments examined in this study. The influence of different water bodies with various temperature, salinity, and 
sediment characteristics on benthic assemblages was also reported for other Arctic regions (e.g. Kara Sea, Jørgensen et al. 1999; Pechora Sea, Denisenko et al. 2003). Benthic assemblages in the Canadian Arctic have been related to water mass temperature and primary production (Stewart et al. 1985), depth and sediment texture (e.g. grain size) (for polychaetes, Bilyard \& Carey 1979; for molluscs, Carey et al. 1984), or grain size and the primary production of overlying water masses (Grebmeier \& Barry 1991). The aforementioned studies revealed that the correlation between physical environmental parameters and assemblage structure is relatively weak. This situation indicates that the structure of benthic assemblages may be influenced by complex interactions between both biotic (e.g. strong local recruitment, simultaneous stages of recolonization etc.) and abiotic variables. Indeed, in a stable Antarctic environment, biotic variables may have a large effect on the distribution of macrobenthic assemblages. Weak linkages have also been observed between assemblages and physical parameters (e.g. deposited phytodetritus, water depth, sediment characteristics) (see Gutt 2000).

\section{Temporal changes in assemblage}

Results from the $\mathrm{F}$ region indicate that temporal variations (at time scales of $<1 \mathrm{mo}$ ) in the structure of benthic assemblages at one site may be greater than spatial variations in community structure between sites (km-scale). This is important in terms of our understanding of temporal variations in benthic community structure. The sampling of the same station over time yielded different values of assemblage structure. Variations in the structure of benthic assemblages over time have been monitored in different habitats following environmental changes such as ecosystem regime shifts (Warwick et al. 2002), oil spills (Warwick \& Clarke 1993), or removal of sewage inputs (Archambault et al. 2001). Inter-annual variations in sea-ice cover within fjords and bays of the Canadian Arctic Archipelago can be extreme from one year to the next (Curtis 1975); this affects local pelagic food supply for the benthos and, in turn, affects the composition of benthic assemblages over time (e.g. Ambrose \& Renaud 1995, Piepenburg et al. $1997 b)$. Temporal variation in the structure of benthic assemblages also gives an indication of the spatial variability that could have existed within samples from an individual survey. Differences among grabs exist, but unfortunately we did not have access to each of the 6 sample grabs from each date of the 4 sampling series or from other Frobisher Bay stations in order to compare the real spatial and temporal vari- ation for a particular site. Given that temporal and spatial variation in benthic assemblage structure may be of the same order of magnitude, comparisons of historical and modern data sets must be undertaken with caution. However, the F benthic community appeared relatively stable when compared at geographical scales, and a quasi-return to the original assemblage was observed for stations F1 and F7 and, to some extent, for F6.

\section{Influence of taxonomic resolution and data transformation}

Studies have shown that transformations of raw data may affect the outcome of multivariate analyses (e.g. Olsgard et al. 1997); however, type of transformation had little effect on the outcome of our results (see also Chapman \& Underwood 1999). This was probably because the variation in abundance among taxa was not great. ANOSIM results differed between regions according to the taxonomic level considered (see Table 5). Dissimilarities occurred up to the Phyla level, but some of these differences disappeared when data were aggregated to the Order level. This was especially true with tests based on densities. ANOSIM is sensitive to the level of taxonomic resolution: values of the R-statistic generally decrease as the level of taxonomic resolution increases (Somerfield \& Clarke 1995, Lasiak 2003). For the $V$ and F regions, most of the significant differences with other regions occurred up to the Phyla level. Therefore, choosing a lower level of taxonomic resolution will not compromise/prejudice the outcome of benthic community analysis for most Arctic regions. Nevertheless, even if the selection of lower taxonomic resolution can save time and money when analysing benthic community structure, this option should not be chosen if the hypothesis posed is thus compromised (Warwick 1988, Ferraro \& Cole 1990, Lasiak 2003).

\section{Use of historical data sets}

The acquisition of new data from the Arctic is essential to improve our comprehension of the ecological processes that govern benthic community structure. In the context of the rapid climate modification of the Arctic, it has become imperative to document benthic communities to track potential changes. Collection of new data must follow the recommendations of research needs (e.g. Carey 1991), e.g. year-round benthic-pelagic studies, long-term time-series, and largescale and co-operative research programmes. The use of high quality data sets from the published literature helps to build a solid base for comparison with modern 
sampling programs. Nevertheless, although the selection of high quality data sets used in this study ensured that the quality of benthic assemblage comparison was consistent, it could not ensure that it was completely accurate. The limited data sets from certain regions and depths restricted some of our conclusions, but were still useful because they reflect the reality of past investigations. Some comparisons of studies that used uniform sampling techniques within polar regions have been discussed (e.g. Piepenburg et al. 1997a, Piepenburg 2005). Our use of species lists (e.g. from $\mathrm{HB}$ ) in this study revealed interesting results; if sampling protocols are comparable or can be standardized, then historical species lists can be used to compare past sampling efforts with more recent ones. The use of indices of biodiversity (taxonomic distinctness and its variation) that are independent of sample size allows stronger comparisons among studies for which sampling effort was uncontrolled, unknown or unequal (Clarke \& Warwick 2001a).

\section{CONCLUSIONS}

Our analyses of historical macrobenthos data from the Canadian Arctic continental shelf revealed that assemblages and biodiversity measurements vary among regions. The observed differences may be associated with various factors such as evolutionary and historical stability, but also with scale-dependent biodiversity measurements and taxonomic resolution. We demonstrated that the impact of salinity and temperature in areas near to important freshwater tributaries (Beaufort Sea and Mackenzie Shelf [BM] and James Bay [JB]) influenced the composition of benthic assemblages. In the context of the rapidly changing Arctic climate, it is important to review the available historical data on benthic marine ecology from the Arctic in order to compare and contrast them with modern investigations. These results provide a basis for future investigation of the biological processes and physical factors responsible for patterns of benthic macrofaunal biodiversity in the Canadian Arctic.

Acknowledgements. We are grateful to Drs. P. Snelgrove, R. D. Hedger and C.W. McKindsey, for comments on an earlier draft of this manuscript. Special thanks to Dr B. Clynick for linguistic assistance. This study depended on the work and publications of several scientists and technicians. We also thank 3 anonymous reviewers for their constructive comments. This project was funded by the Canadian Arctic Shelf Exchange Study (CASES) Subproject 7: Benthic Processes and Carbon Cycling, in the form of a postdoctoral fellowship to M.C. CASES is a project funded by the Natural Sciences and Engineering Research Council of Canada (NSERC). This project is also supported by the Department of Fisheries and Oceans, Canada.

\section{LITERATURE CITED}

ACIA (Arctic Climate Impact Assessment) (2005) Arctic climate impact assessment. Cambridge University Press, Cambridge

Aitken AE, Fournier J (1993) Macrobenthos communities of Cambridge, Mcbeth and Itirbilung Fjords, Baffin Island, Northwest-Territories, Canada. Arctic 46:60-71

Ambrose GAJ, Renaud PE (1995) Benthic response to water column productivity patterns: evidence for benthicpelagic coupling in the Northeast Water Polynya. J Geophys Res 94:4411-4421

Archambault P, Banwell K, Underwood AJ (2001) Temporal variation in the structure of intertidal assemblages following the removal of sewage. Mar Ecol Prog Ser 222:51-62

Atkinson EG, Wacasey JW (1987) Sedimentation in Arctic Canada: particulate organic carbon flux to a shallow marine benthic community in Frobisher Bay. Polar Biol 8: 3-8

Atkinson EG, Wacasey JW (1989a) Benthic invertebrates collected from Hudson Bay, Canada, 1953 to 1965. Can Data Rep Fish Aquat Sci No. 744

Atkinson EG, Wacasey JW (1989b) Benthic invertebrates collected from the western Canadian Arctic, 1951 to 1985. Can Data Rep Fish Aquat Sci No. 745

Barber DG, Hanesiak JM (2004) Meteorological forcing of sea ice concentrations in the southern Beaufort Sea over the period 1979 to 2000. J Geophys Res 109:C06014, doi: 10.1029/2003JC002027

Barnes DKA (1999) The influence of ice on polar nearshore benthos. J Mar Biol Assoc UK 79:401-407

Barnes RD (1987) Invertebrate zoology. Saunders College, Philadelphia

Belchansky GI, Douglas DC, Alpatsky IV, Platonov NG (2004) Spatial and temporal multiyear sea ice distributions in the Arctic: a neural network analysis of SSM/I data, 1988-2001. J Geophys Res 109:C10017, doi:10.1029/2004JC002388

Bertocci I, Maggi E, Vaselli S, Benedetti-Cecchi L (2005) Contrasting effects of mean intensity and temporal variation of disturbance on a rocky seashore. Ecology 86: 2061-2067

Bilyard GR, Carey AG Jr (1979) Distribution of western Beaufort Sea polychaetous annelids. Mar Biol 54:329-339

Blasco SM, Shearer JM, Myers RA (1998) Seabed scouring by sea-ice: scouring process and impact rates: Canadian Beaufort Shelf. 13th Int Symp Okhotsk Sea and Sea Ice. Proc Ice Scour Arctic Mar Pipelines Workshop, Feb. 1-4, Mombetsu, Hokkaido, Japan, p 53-58

Bluhm BA, MacDonald IR, Debenham C, Iken K (2005) Macro- and megabenthic communities in the high Arctic Canada Basin: initial findings. Polar Biol 28:218-231

Bray JR, Curtis JT (1957) An ordination of the upland forest of Southern Wisconsin. Ecol Monogr 27:225-349

Carey AG Jr (1991) Ecology of North American Arctic continental shelf benthos: a review. Cont Shelf Res 11:865-883

Carey AG Jr, Scott PH, Walters KR (1984) Distributional ecology of shallow southwestern Beaufort Sea (Arctic Ocean) bivalve Mollusca. Mar Ecol Prog Ser 17:125-134

Carmack EC, MacDonald RW (2002) Oceanography of the Canadian shelf of the Beaufort Sea: a setting for marine life. Arctic 55:29-45

Chapman MG, Underwood AJ (1999) Ecological patterns in multivariate assemblages: information and interpretation of negative values in ANOSIM tests. Mar Ecol Prog Ser 180:257-265

Clarke KR (1993) Non-parametric analyses of changes in community structure. Aust J Ecol 18:117-143 
Clarke KR, Ainsworth M (1993) A method of linking multivariate community structure to environmental variables. Mar Ecol Prog Ser 92:205-219

Clarke KR, Gorley RN (2001) PRIMER v5.2.9: user manual/ tutorial. PRIMER-E, Plymouth Marine Laboratory, Plymouth

Clarke KR, Warwick RM (1994) Similarity-based testing for community pattern: the two-way layout with no replication. Mar Biol 118:167-176

Clarke KR, Warwick RM (1998) A taxonomic distinctness index and its statistical properties. J Appl Ecol 35:523-531

Clarke KR, Warwick RM (2001a) Change in marine communities: an approach to statistical analysis and interpretation. Plymouth Marine Laboratory, Plymouth

Clarke KR, Warwick RM (2001b) A further biodiversity index applicable to species lists: variation in taxonomic distinctness. Mar Ecol Prog Ser 216:265-278

Comiso JC, Parkinson CL (2004) Satellite-observed changes in the Arctic. Physics Today 57:38-44

Conlan K, Kvitek R (2005) Recolonization of soft-sediment ice scours on an exposed Arctic coast. Mar Ecol Prog Ser 286: $21-42$

Connell JH (1978) Diversity in tropical rain forest and coral reefs. Science 199:1302-1310

Cross WE, Thomson DH (1987) Effects of experimental releases of oil and dispersed oil on arctic nearshore macrobenthos I. Infauna. Arctic 40:184-200

Cross WE, Martin CM, Thomson DH (1987) Effects of experimental releases of oil and dispersed oil on arctic nearshore macrobenthos II. Epibenthos. Arctic 40: 201-210

Curtis MA (1975) The marine benthos of Arctic and sub-Arctic continental shelves. Polar Rec 17:595-626

Denisenko SG, Denisenko NV, Lehtonen KK, Andersin AB, Laine AO (2003) Macrozoobenthos of the Pechora Sea (SE Barents Sea): community structure and spatial distribution in relation to environmental conditions. Mar Ecol Prog Ser 258:109-123

Downes B, Barmuta LA, Fairweather PG, Faith DP, Keough M, Lake P, Mapstone BD, Quinn G (2002) Monitoring ecological impacts: concept and practice in flowing waters. Cambridge University Press, Cambridge

Dunton KH, Goodall JL, Schonberg SV, Grebmeier JM, Maidment DR (2005) Multi-decadal synthesis of benthicpelagic coupling in the western arctic: role of cross-shelf advective processes. Deep-Sea Res II 52:3462-3477

Dyke AS, Dale JE, McNeely RN (1996a) Marine molluscs as indicators of environmental change in glaciated North America and Greenland during the last 18,000 years. Géogr Phys Quat 50:125-184

Dyke AS, Hooper J, Savelle JM (1996b) A history of sea ice in the Canadian Arctic Archipelago based on postglacial remains of the bowhead whale (Balaena mysticetus). Arctic 49:235-255

Ellingsen KE, Gray JS (2002) Spatial patterns of benthic diversity: is there a latitudinal gradient along the Norwegian continental shelf? J Anim Ecol 71:373-389

Ferraro SP, Cole FA (1990) Taxonomic level and sample-size sufficient for assessing pollution impacts on the Southern California Bight macrobenthos. Mar Ecol Prog Ser 67: 251-262

Field JG, Clarke KR, Warwick RM (1982) A practical strategy for analyzing multispecies distribution patterns. Mar Ecol Prog Ser 8:37-52

Flach E, de Bruin W (1999) Diversity patterns in macrobenthos across a continental slope in the NE Atlantic. J Sea Res 42:303-323
Gagnon AS, Gough WA (2005) Trends in the dates of ice freeze-up and breakup over Hudson Bay, Canada. Arctic 58:370-382

Gordillo S, Aitken AE (2000) Palaeoenvironmental interpretation of late quaternary marine molluscan assemblages, Canadian Arctic Archipelago. Géogr Phys Quat 54: 301-315

Gordillo S, Aitken AE (2001) Postglacial succession and palaeoecology of Late Quaternary macrofaunal assemblages from the central Canadian Arctic Archipelago. Boreas 30:61-72

Grainger EH (1975) A marine ecology study in Frobisher Bay Arctic Canada. In: Cameron TWM, Billingsley LW (eds) Energy flow-its biological dimensions. Can Comm Int Biol Programme, R Soc Can, Ottawa, p 261-266

Gray JS (2000) The measurement of marine species diversity, with an application to the benthic fauna of the Norwegian continental shelf. J Exp Mar Biol Ecol 250:23-49

Gray JS (2001) Antarctic marine benthic biodiversity in a world-wide latitudinal context. Polar Biol 24:633-641

Gray JS, Clarke KR, Warwick RM, Hobbs G (1990) Detection of initial effects of pollution on marine benthos: an example from the Ekofisk and Eldfisk oil fields, North Sea. Mar Ecol Prog Ser 66:285-300

Grebmeier JM, Barry JP (1991) The influence of oceanographic processes on pelagic-benthic coupling in polar regions: a benthic perspective. J Mar Syst 2:495-518

Gutt J (2000) Some 'driving forces' structuring communities of the sublittoral Antarctic macrobenthos. Antarct Sci 12: 297-313

Harkantra SN, Rodrigues NR (2004) Numerical analyses of soft bottom macroinvertebrates to diagnose the pollution in tropical coastalwaters. Environ Monit Assess 93: $251-275$

Hewitt JE, Thrush SE, Halliday J, Duffy C (2005) The importance of small-scale habitat structure for maintaining beta diversity. Ecology 86:1619-1626

Hill PR, Lewis CP, Desmarais S, Kauppaymuthoo V, Rais H (2001) The Mackenzie Delta: sedimentary processes and facies of a high-latitude, fine-grained delta. Sedimentology 48:1047-1078

Huston M (1979) General hypothesis of species-diversity. Am Nat 113:81-101

Jørgensen LL, Pearson TH, Anisimova NA, Gulliksen B, Dahle S, Denisenko SG, Matishov GG (1999) Environmental influences on benthic fauna associations of the Kara Sea (Arctic Russia). Polar Biol 22:395-416

Kendall MA (1996) Are Arctic soft sediment macrobenthic communities impoverished? Polar Biol 16:393-399

Lasiak T (2003) Influence of taxonomic resolution, biological attributes and data transformations on multivariate comparisons of rocky macrofaunal assemblages. Mar Ecol Prog Ser 250:29-34

Lubinsky I (1980) Marine bivalve molluscs of the Canadian Central and Eastern Arctic: faunal composition and zoogeography. Can Bull Fish Aquat Sci 207:1-73

MacLaren MAREX (1978) Report on marine benthic invertebrates of the southern Davis Strait and Ungava Bay for Imperial Oil Limited, Aquitaine Company of Canada Limited and Canada Cities Service Limited. MacLaren MAREX, Dartmouth

Macpherson E (2002) Large-scale species-richness gradients in the Atlantic Ocean. Proc R Soc Lond B 269:1715-1720

Magurran AE (2004) Measuring biological diversity. Blackwell Science, Malden, MA

Montgomery DC (1991) Design and analysis of experiments. John Wiley \& Sons, Toronto 
Moritz RE, Bitz CM, Steig EJ (2002) Dynamics of recent climate change in the Arctic. Science 297:1497-1502

Mumby PJ (2001) Beta and habitat diversity in marine systems: a new approach to measurement, scaling and interpretation. Oecologia 128:274-280

Olsgard F, Somerfield PJ, Carr MR (1997) Relationships between taxonomic resolution and data transformations in analyses of a macrobenthic community along an established pollution gradient. Mar Ecol Prog Ser 149:173-181

Pechenik JA (1991) Biology of the invertebrates, 2nd edn. William C Brown, Dubuque

Piepenburg D (2005) Recent research on Arctic benthos: common notions need to be revised. Polar Biol 28:733-755

Piepenburg D, Voss J, Gutt J (1997a) Assemblages of sea stars (Echinodermata: Asteroidea) and brittle stars (Echinodermata: Ophiuroidea) in the Weddell Sea (Antarctica) and off Northeast Greenland (Arctic): a comparison of diversity and abundance. Polar Biol 17:305-322

Piepenburg D, Ambrose GAJ, Brandt A, Renaud PE, Ahrens MJ, Jensen P (1997b) Benthic community patterns reflect water column processes in the Northeast Water Polynya (Greenland). J Mar Syst 10:467-482

Piepenburg D, Schmid MK, Gerdes D (2002) The benthos off King George Island (South Shetland Islands, Antarctica): further evidence for a lack of a latitudinal biomass dine in the Southern Ocean. Polar Biol 25:146-158

Polyakov IV, Beszczynska A, Carmack EC, Dmitrenko IA and 19 others (2005) One more step toward a warmer Arctic. Geophys Res Lett 32:L17605, doi:17610.11029/ 12005GL023740

Rex MA, Stuart CT, Hessler RR, Allen JA, Sanders HL, Wilson GDF (1993) Global-scale latitudinal patterns of species diversity in the deep-sea benthos. Nature 365:636-639

Sanders HL (1969) Benthic marine diversity and the stability time hypothesis. Brookhaven Symp Biol 22:71-81

Sanders HL (1977) Evolutionary ecology and the deep sea benthos. Acad Nat Sci Phila Spec Publ 12:223-243

Sanders HL, Hessler RR (1969) Ecology of the deep-sea benthos. Science 163:1419-1424

SAS (1999) The SAS system for Windows, release 8.02 edn. SAS Institute, Cary, NC

Scherrer B (1984) Biostatistique. Gaëtan Morin, Montréal

Serreze MC, Maslanik JA, Scambos TA, Fetterer F and 6 others (2003) A record minimum arctic sea ice extent and area in 2002. Geophys Res Lett 30:1110 doi:10.1029/ 2002GL016406

Somerfield PJ, Clarke KR (1995) Taxonomic levels, in marine community studies, revisited. Mar Ecol Prog Ser 127: 113-119

Somerfield PJ, Gage JD (2000) Community structure of the benthos in Scottish sea-lochs. IV. Multivariate spatial pattern. Mar Biol 136:1133-1145

Editorial responsibility: Howard Browman (Associate Editorin-Chief), Storebø, Norway
Stewart PL (1983) Measurements of benthic macroinvertebrates standing crop from the Canadian continental shelf and slope of Southern Davis Strait and Ungava Bay. Can J Fish Aquat Sci 40:652-658

Stewart PL, Pocklington P, Cunjak RA (1985) Distribution, abundance and diversity of benthic macroinvertebrates on the Canadian continental shelf and slope of Southern Davis Strait and Ungava Bay. Arctic 38:281-291

Stone M (1974) Cross-validatory choice and assessment of statistical predictions (with discussion). J R Stat Soc B 36: 111-147

Syvitski JPM, Farrow GE, Atkinson RJA, Moore PG, Andrews JT (1989) Baffin Island fjord macrobenthos - bottom communities and environmental significance. Arctic 42:232-247

Teixido N, Garrabou J, Arntz W (2002) Spatial pattern quantification of Antarctic benthic communities using landscape indices. Mar Ecol Prog Ser 242:1-14

Thomson DH (1982) Marine benthos in the Eastern Canadian High Arctic: multivariate analyses of standing crop and community structure. Arctic 31:61-74

Thrush SF, Hewitt JE, Funnell GA, Cummings VJ, Ellis J, Schultz D, Talley D, Norkko A (2001) Fishing disturbance and marine biodiversity: role of habitat structure in simple soft-sediment systems. Mar Ecol Prog Ser 221:255-264

Wacasey JW, Atkinson EG, Kinlough L (1976) Zoobenthos data from James Bay, 1959, 1974. Fish Mar Serv Res Dev Tech Rep No. 661

Wacasey JW, Atkinson EG, Derick L, Weinstein A (1977) Zoobenthos data from the southern Beaufort Sea, 1971-1975. Fish Mar Serv Res Dev Tech Rep No. 41

Wacasey JW, Atkinson EG, Glasspoole L (1979) Zoobenthos data from upper Frobisher Bay, 1967-1973. Can Data Rep Fish Aquat Sci No. 164

Wacasey JW, Atkinson EG, Glasspoole L (1980) Zoobenthos data from inshore stations of upper Frobisher Bay, 1969-1976. Can Data Rep Fish Aquat Sci No. 205

Warwick RM (1988) The level of taxonomic discrimination required to detect pollution effects on marine benthic communities. Mar Pollut Bull 19:259-268

Warwick RM, Clarke KR (1993) Comparing the severity of disturbance: a meta-analysis of marine macrobenthic community data. Mar Ecol Prog Ser 92:221-231

Warwick RM, Ashman CM, Brown AR, Clarke KR and 6 others (2002) Inter-annual changes in the biodiversity and community structure of the macrobenthos in Tees Bay and the Tees estuary, UK, associated with local and regional environmental events. Mar Ecol Prog Ser 234:1-13

Willig MR, Kaufman DM, Stevens RD (2003) Latitudinal gradients of biodiversity: pattern, process, scale, and synthesis. Annu Rev Ecol Syst 34:273-309

Zar JH (1999) Biostatistical analysis. Prentice-Hall, Englewood Cliffs, New Jersey

Submitted: November 15, 2005; Accepted: June 20, 2006

Proofs received from author(s): January 31, 2007 